\title{
LOS ANARQUISTAS DE HABLA HISPANA EN ESTADOS UNIDOS Y SUS REDES TRANSNACIONALES. EL PERIÓDICO EL DESPERTAR DE BROOKLYN (1891-1902)
} Spanish-speaking anarchists in the United States and their transnational networks. El Despertar, Brooklyn (1891-1902)

\author{
SUSANA SUEIRO SEOANE \\ Universidad Nacional de Educación a Distancia \\ ssueiro@geo.uned.es \\ Cómo citar/Citation \\ Sueiro Seoane, S. (2019). \\ Los anarquistas de habla hispana en Estados Unidos y sus redes transnacionales. \\ El periódico El Despertar de Brooklyn (1891-1902). \\ Historia y Política, 42, 25-53 \\ doi: https://doi.org/10.18042/hp.42.02
}

(Recepción: 21/12/2018; evaluación: 12/03/2019; aceptación: 13/05/2019; publicación: 13/12/2019)

Resumen

Este texto parte de la premisa de que el movimiento anarquista solo puede comprenderse en toda su dimensión y complejidad si se analiza como una red transnacional que se expandió por muchos países de varios continentes. El carácter transnacional del anarquismo atañe también a sus publicaciones, que experimentaron un enorme trasiego, con frecuencia de una orilla a otra del Atlántico, y conectaron entre sí los distintos movimientos anarquistas nacionales de Europa y América. Es el caso del periódico El Despertar de Brooklyn, cuya influencia traspasó ampliamente las fronteras de Estados Unidos. Este texto es un intento de sacar a la luz las conexiones y la estrecha red de contactos de los anarquistas hispanos en Estados Unidos, tanto entre grupos como entre individuos concretos, poniendo el foco en la figura de Pedro Esteve, que durante tres décadas, en el tránsito del siglo XIX al xx, realizó un inmenso trabajo de agitación y propaganda en 
los medios obreros españoles, italianos y cubanos de Estados Unidos, a través fundamentalmente de los periódicos que editó o en cuya redacción fue la figura clave.

\title{
Palabras clave
}

Anarquismo; prensa anarquista; El Despertar; Pedro Esteve; Estados Unidos.

\begin{abstract}
This text is based on the premise that the anarchist movement can only be understood in its full dimension and complexity if it is analysed as a transnational network that spread through many countries in various continents. The transnational character of Anarchism also affects its publications, which saw a flurry of activity, often from one coast of the Atlantic to the other, and the different national Anarchist movements of Europe and America thus connected with each other. This is the case of El Despertar, a Spanish-language Brooklyn periodical whose influence spread well beyond the borders of the U.S. This text is an attempt to bring to light the connections and the close network of contacts, both amongst groups and particular individuals, of the Hispanic anarchists in the U.S., spotlighting the figure of Pedro Esteve who, for three decades during the course of the XIX al Xx Centuries, carried out an immense work of rallying and propaganda in the Spanish, Italian and Cuban labour movement of the United States, mainly through the periodicals he published or those in whose editorial staff he was a key figure.
\end{abstract}

\section{Keywords}

Anarchism; anarchist periodicals; El Despertar; Pedro Esteve; United States of America. 


\section{SUMARIO}

I. INTRODUCCIÓN. II. LA FUNDACIÓN DE EL DESPERTAR. III. EL MUNDO DE LAS TABAQUERÍAS Y LA INSTITUCIÓN DE «LA LECTURA». IV. LA RELACIÓN CON EL PRODUCTOR DE BARCELONA.V. PEDRO ESTEVE, FIGURA CLAVE. VI. LOS ASUNTOS DE ESPAÑA Y LA «PROPAGANDA POR EL HECHO». VII. CONCLUSIONES. BIBLIOGRAFÍA.

\section{INTRODUCCIÓN}

En el periodo de tránsito del siglo xix al xx, la época de esplendor del movimiento anarquista en el mundo, se publicaron una ingente cantidad de periódicos anarquistas, ya que una de las principales actividades de cualquier grupo anarquista al constituirse era editar su periódico. La mayoría de ellos tuvieron tiradas limitadas y corta vida debido a las dificultades de diversa índole para su edición, sobre todo de financiación. Su déficit y precariedad económica eran proverbiales. Pero algunos, los más importantes, se publicaron durante años, traspasaron las fronteras nacionales y de distribuyeron por diversos países e, incluso, por varios continentes.

Estos periódicos transnacionales, además de cumplir funciones de propaganda y de socialización del obrero, hicieron de intermediarios tejiendo una red de individuos y colectividades militantes en muy diversos lugares, que estuvieron en permanente comunicación. A través de cartas, avisos, circulares, noticias, etc., enviadas a la Redacción, cualquiera de los miembros de la red podía dar a conocer en poco tiempo a todos los demás un pensamiento o proposición, «y el iniciador o proponente saber prontamente la opinión de sus compañeros y con cuántos y quiénes puede contar $»^{1}$, en palabras de Pedro Esteve, gran protagonista de la red anarquista a la que dedicamos este artículo.

En concreto, queremos centrar nuestra atención en El Despertar, editado en Brooklyn ${ }^{2}$ entre 1891 y 1902, un periódico quincenal hecho por obreros tabaqueros hispanohablantes (cubanos y españoles), pero que era leído también en las tabaquerías de Florida (de Tampa y Cayo Hueso) y en

\footnotetext{
Esteve (1900).

2 Brooklyn fue una ciudad independiente hasta 1898, en que se convirtió en un barrio de Nueva York.
} 
las de Cuba, y asimismo se distribuía en países más lejanos, como Argentina y España ${ }^{3}$.

\section{LA FUNDACIÓN DE EL DESPERTAR}

A principios de 1891, un reducido número de trabajadores tabaqueros cubanos y españoles residentes en Nueva York constituyeron el grupo Parsons en honor a uno de los famosos anarquistas ajusticiados en Chicago en 1887. Entre sus primeras tareas estuvo la fundación, en febrero de 1891, del periódico El Despertar, que llegaría a tener gran difusión entre el proletariado de habla hispana de Estados Unidos, y cuya primera sede estuvo en el 181 de Adams Street, junto al puente de Brooklyn. Los obreros que constituían el Consejo de Redacción leían, discutían y aprobaban o rechazaban de común acuerdo los manuscritos que se publicaban ${ }^{4}$.

Desde su aparición, El Despertar tuvo una red de agentes que lo distribuían en diversas ciudades de Estados Unidos, como Tampa o Cayo Hueso (Florida), y también en otros países como Cuba, Argentina y España. Sus editores formaron parte de una red transnacional, difusa y opaca, con capacidad para tomar decisiones de trascendencia, compuesta por personas poco o nada conocidas por la historiografía, en cuyo epicentro, como veremos, se sitúa el impresor Pedro Esteve, muy consciente de la importancia del transnacionalismo para el desarrollo del movimiento anarquista. Los periódicos que editó, primero en Cataluña y luego en Cuba y en Estados Unidos, tuvieron un papel central en esa conexión transnacional.

En un principio ejerció como administrador Manuel Martínez Abello, cubano al que despidieron del taller de tabaquería donde trabajaba ${ }^{5}$ por figurar con ese cargo en la cabecera del periódico. No eran raras las noticias de tabaqueros que habían sido «rebajados», esto es, despedidos por ser anarquistas o por ser «hombres de El Despertar». Por eso, sus artículos solían ser anónimos o escritos con seudónimo: el grupo prefería el anonimato para no sufrir represalias.

Aunque José Cayetano Campos, tabaquero y tipógrafo nacido en la Habana (1850-1902), no aparece en la cabecera, es una figura fundamental en El Despertar desde su origen, junto con Luis Barcia, que era "peninsular».

3 He consultado la colección de este periódico en el Archivo del Instituto Internacional de Historia Social de Amsterdam (IISH). Está disponible también en el Arquivo da Emigración Galega (Santiago de Compostela).

4 «La organización obrera», El Despertar, 1-1-1892.

5 «Por qué soy anarquista», El Despertar, 1-6-1891. 
Campos tenía hijos pequeños, razón por la cual el grupo decidió que no debía aparecer como editor ${ }^{6}$. La sede del periódico empezó siendo el domicilio de Martínez Abello, pero al tener que ausentarse «por asuntos de familia» se avisó a los lectores para que se dirigiesen a una nueva dirección, el 37 de Columbia Heights, Brooklyn, que probablemente era el domicilio de Luis Barcia. Finalmente, el grupo decidió que fuera Barcia quien apareciera como redactor responsable, o sea como director, lo que le acarreó también quedarse sin trabajo en el taller de tabaquería, aunque, según el periódico, esa represalia le infundió más ánimo para la lucha, y le impelió a escribir mucho y contribuir con lo que económicamente podía al sostén de la publicación 7 .

Luis Barcia Quilabert, que firmaba algunos artículos con sus iniciales, L. B. Q., era un obrero tabaquero español, si bien su primer oficio fue cajista. Había trabajado en diversas imprentas en Cuba y luego en Estados Unidos — en Cayo Hueso y Tampa (Florida) —, había sido corresponsal de El Productor de La Habana ${ }^{8}$ y mantenía muchas conexiones con los anarquistas cubanos. Tenía entonces 26 años?

Barcia y Campos comparten el oficio de impresor. En el mundo de las imprentas se hacen anarquistas, leyendo libros sobre doctrinas «social-anárquicas». Uno y otro empezaron su vida laboral y militante en Cuba, pero emigraron a Estados Unidos y acabaron estableciéndose en Nueva York. Para complementar su sueldo de cajistas, que era muy bajo, aprendieron el arte tabaquero trabajando como torcedores de tabaco ${ }^{10}$.

Luis Barcia fue un año redactor responsable de El Despertar hasta que, por asuntos privados, según el periódico, decidió volver a La Habana. Una comisión del periódico acudió a despedirle cuando abandonó Nueva York el 19 de diciembre de 1891 y le rindió tributo dedicándole el editorial del número siguiente. Desde Cuba, Barcia siguió colaborando mucho en El Despertar.

6 En la partida de nacimiento de una hija de Campos, Isabel, consta que ha nacido en Brooklyn en mayo de 1892; que el padre, de nombre José Cayetano Campos, tiene 42 ańos y la madre, Isabel Durio, 36. En esa misma partida, consta que el oficio de J. C. Campos es impresor. Agradezco al profesor Chris Castañeda (California State University) que me proporcionara copia de la misma.

$7 \quad$ El Despertar, 1-11-1891, p. 21.

8 A semejanza de El Productor de Barcelona, Roig San Martin fundó en 1887 El Productor de La Habana y ambos periódicos mantuvieron vínculos muy estrechos. El Productor de Barcelona llegaba a la isla y el de la Habana se podía leer en España.

9 «Colaboración. ¡Odio a los curas!, por L. B. Q., junio de 1890», El Despertar, 15-5-1891.

10 «Despedida», El Despertar, 1-1-1892, p. 1. 
Luego se trasladó a Tampa, Florida, donde contribuyó a fundar el periódico El Esclavo, en junio de 1894.

\section{EL MUNDO DE LAS TABAQUERÍAS Y LA INSTITUCIÓN DE «LA LECTURA»}

Como es lógico, teniendo en cuenta quiénes eran los redactores más importantes, El Despertar tenía como tema de atención prioritario las condiciones de trabajo y las huelgas en los diferentes talleres de tabaquería de Nueva York, así como de Florida y, en menor medida, de Cuba, e incluso de Boston o Toronto (Canadá). Los corresponsales en Tampa y Cayo Hueso (Florida), donde había una gran concentración de talleres, mandaban sus cartas a $E l$ Despertar con una periodicidad frecuente. A su vez, había un fuerte movimiento de solidaridad obrera entre estas localidades y Cuba, a los dos lados del estrecho de la Florida ${ }^{11}$.

En las crónicas tabaqueras del periódico se critica a los obreros sumisos, "esclavos», "mansos carneros», "con la venda de la ignorancia en los ojos», que llaman al Despertar "papelucho" o "periodicucho» y se rebelan precisamente contra quienes quieren romper sus cadenas. Con frecuencia se lee que algún capataz de un taller amenaza con despedir a «los hombres de El Despertar» y a todo aquel que en los talleres proporcione datos para el periódico anarquista. En un número se comenta que, en un determinado taller, «el último Despertar cayó como una bomba de dinamita» y que un obrero afín al capataz «echó sapos y culebras por boca en contra de la Redacción del Despertar y de todos los que escriben en él $»^{12}$. «Sabemos — se dice en otra ocasión- que esos señores (empresarios tabaqueros) miran con harto disgusto a los hombres de $E l$ Despertar» ${ }^{13}$.

La industria tabaquera fue muy anarquista, no solo por emplear a obreros españoles, cubanos e italianos que lo eran, muchas veces ya en sus países de origen, sino por la decisiva influencia de la figura de los «lectores» que, tanto en Cuba como en Estados Unidos, leían literatura y prensa radical en voz alta

11 Cuando, en tiempos de crisis o huelgas, los obreros de Cuba se quedaban sin trabajo, muchos se trasladaban a Florida y los obreros cubanos residentes en Estados Unidos recaudaban fondos y enviaban auxilios económicos, pagándoles el pasaje para viajar a Tampa o Cayo Hueso.

12 El Despertar, 17-10-1891.

13 Para contrarrestar la influencia creciente del periódico de Brooklyn, los dueños de las tabaquerías de Nueva York comenzaron a publicar The Tobacco Leaf. 
a los obreros mientras trabajaban enrollando puros habanos ${ }^{14}$. Era una costumbre libre de toda injerencia patronal y gubernativa ${ }^{15}$. Solo los operarios del taller tenían derecho a intervenir en cuanto a la lectura se refería y, durante la misma, no temían exponer francamente su opinión sobre cualquier asunto ${ }^{16}$. Los propios obreros elegían a su lector, que debía tener una voz bonita y persuasiva. El día de paga, generalmente el sábado, se colocaba en la puerta del taller para cobrar su sueldo a base de las cuotas voluntarias de los obreros. Bernardo Vega, un tabaquero puertorriqueńo de Nueva York, recuerda que en todas las fábricas de tabaco se observaba un silencio de iglesia durante la lectura. Al final, se iniciaba la discusión sobre lo leído. Se hablaba de una mesa a otra, sin interrumpir el trabajo ${ }^{17}$. La institución de la lectura hizo de los tabaqueros el sector más ilustrado y culto de la clase obrera. La fábrica de tabacos era una universidad popular que enseñaba a los trabajadores cosas de las que jamás habían oído hablar. La cultura de la fábrica se extendía a los cafés y centros sociales, donde los obreros conversaban y discutían las obras que se estaban leyendo. Los anarquistas defendían con ahínco esta «bellísima costumbre, digna de ser imitada y adaptada a los oficios que sea posible» ${ }^{18}$, que favorecía la divulgación de los principios ácratas porque se daba preferencia a la lectura de periódicos y revistas de carácter obrero o social.

A principios de 1894 había en Nueva York unos tres mil talleres de cigarros puros. Aquel fue un año de aguda crisis económica en que se disparó la tasa de paro y las tabaquerías se vieron muy afectadas, con despidos de obreros y bajada de salarios, lo que llevó a la constitución de la Unión de Torcedores de Tabaco Habano de Nueva York, conocida popularmente como La Defensa, de carácter anarquista, cuyo máximo dirigente fue J. C. Campos. Al contrario que la mucho más amplia Cigars' Makers International Union dirigida por Samuel Gompers, La Defensa se componía de una minoría radical que aspiraba a romper con los viejos moldes reformistas del unionismo norteamericano. $E l$ Despertar aumentó por entonces su difusión, lo que llevó a la «la agrupación sostenedora» del periódico a anunciar, el 10 de junio de 1894, que pasaba de ser quincenal a publicarse cada diez días, los 10, 20 y 30 de cada mes. La pretensión era poder hacer un semanario con el tiempo, si las ayudas recibidas se incrementaban, lo que consiguieron durante una temporada.

\footnotetext{
Tinajero, 2007.

El Despertar, 11-12-1902.

Esteve (1900): 81-82.

Vega (1984): 41.

18 El Despertar, 10-1-1895.
} 


\section{LA RELACIÓN CON EL PRODUCTOR DE BARCELONA}

Desde el mismo momento de su fundación, El Despertar tuvo una estrecha relación con varios periódicos anarquistas de otros países, algunos muy alejados geográficamente, pero con los que hubo una relación intensa a través de sus corresponsales y de unas pocas personas que establecieron una densa red de contactos y fuertes vínculos transnacionales. El problema para el historiador es que las relaciones entre ellos no siempre son claras puesto que los anarquistas, en muchas ocasiones, escribían sin firma, o bien ocultaban sus nombres bajo seudónimos, y en la cabecera podía aparecer como editor alguien del grupo que no era el personaje central porque, por alguna razón, convenía que aquel no fuese visible, así que el historiador se ve obligado a hacer una labor en gran parte detectivesca. Al hacerla, emerge un claro paralelismo entre periódicos muy semejantes que se editaban a miles de kilómetros de distancia. La hipótesis que sostenemos es que la conexión entre ellos obedece a una planificación y organización por parte una serie de figuras destacadas del anarquismo transnacional, que tenían un plan definido de actuación y un proyecto insurreccional en la sombra, pero evidente cuando se miran con atención los periódicos en los que participaron y la estrecha relación transnacional entre ellos.

Para entender El Despertar, y su trayectoria y evolución, necesitamos referirnos a otro periódico anarquista que se editaba a miles de kilómetros, en otro continente, El Productor de Barcelona (1887-1893), diario al principio, semanario después, que cruzó el Atlántico y se difundió por América, convirtiéndose en una de las cabeceras más influyentes del pensamiento anárquico internacional. Dos de sus integrantes, Adrián del Valle y Pedro Esteve, este último el personaje central del periódico barcelonés, acabarían formando parte esencial del periódico de Nueva York. El Productor insertaba en casi todos los números extractos de lo publicado por «nuestro querido colega» $E l$ Despertar de Nueva York.

J. C. Campos había sido corresponsal de El Productor de Barcelona desde su primer número ${ }^{19}$. Sus crónicas sobre los famosos Mártires de Chicago tuvieron gran repercusión entre los obreros españoles ${ }^{20}$. Cuando Adrián del

19 Antoni Pellicer, uno de los inspiradores del periódico barcelonés, le había conocido durante un viaje por México, Cuba y Estados Unidos entre 1871 y 1874 , y a partir de ahí, la colaboración de Campos con los compañeros de España fue constante.

20 Sueiro (2014). Fue J. C. Campos - tanto en El Productor de Barcelona, donde publicó sus correspondencias desde Nueva York, como en El Despertar de Nueva York- quien se encargó de construir el relato en español en torno a los mártires de 
Valle, colaborador asiduo de El Productor, y Pedro Esteve, el alma de este periódico, emigraron a Estados Unidos en 1892, tuvieron ocasión de estrechar los vínculos de íntima colaboración y amistad con J. C. Campos en $E l$ Despertar.

Adrián del Valle, nacido en Barcelona, seguramente de buena familia («tenía pinta de señorito», según él mismo dice), se hizo libertario a los 15 años leyendo El Productor ${ }^{21}$ y allí, en aquel periódico, comenzó su labor de periodista cuando era "un jovenzuelo de rostro lampiño», y colaboraba con asiduidad con trabajos anónimos o firmando como Palmiro o Palmiro de Lidia. Del Valle era en la Redacción de El Productor el compañero de menos edad, apenas un adolescente. Pedro Esteve fue su mentor en el periódico, le protegió y se convirtió en su amigo íntimo. Confiaba en sus dotes literarias y le animaba a escribir. Fueron inseparables en aquella época barcelonesa.

Tras la famosa sublevación anarquista de Jerez de la Frontera, en enero de $1892^{22}$, Esteve huyó en compañía de Adrián del Valle, se refugió en París, luego en Bélgica y viajó finalmente a Londres. Durante este viaje, los dos amigos conocieron personalmente a destacadas figuras del movimiento anarquista, como Peter Kropotkin ${ }^{23}$, Jean Grave o Charles Malato.

Del Valle es el primero en viajar a Estados Unidos. Llegó al puerto de Nueva York el 22 de febrero de 1892 a bordo del buque Etruria, que había zarpado de Liverpool. Tenía 19 años. Así recordaba a Esteve y su llegada a Nueva York:

¿Cómo olvidar (a Esteve), al que fue mi más íntimo amigo en los años de juventud, a la vez guía ideológico y carińoso estimulador de mis inclinaciones literarias? [...]. A últimos de febrero de 1892, Esteve se despidió de mí en Londres para volver a España. Yo seguí viaje para Nueva York. En esta última ciudad me

Chicago. Cada año refería con detalle los actos de recuerdo organizados en distintas ciudades de Estados Unidos, que transcurrían en días distintos, según la celebración fuese de los socialistas o los anarquistas.

21 «Evocando el pasado (1886-1891)», La Revista Blanca, 15-7-1927 a 15-9-1927.

22 Se especuló sobre la posible implicación en la sublevación del italiano Errico Malatesta, que por entonces estaba de gira en España, en compañía de Pedro Esteve. Algunos de los presos por «lo de Jerez» afirmaron que se les había dicho que Malatesta iba a dar un discurso. Los campesinos, a pesar de que muchos no sabían leer, lo conocían gracias a la difusión de la prensa anarquista, que era leída en voz alta en las gañanías y en los campos.

23 Esteve y la mayoría de los colaboradores de El Productor eran kropotkianos. Como homenaje a Kropotkin, al que consideró su maestro, Adrián del Valle publicó en 1925 el opúsculo biográfico Kropotkin, vida y obras. 
recibió otro amigo y compañero inolvidable, J. C. Campos, a quien Esteve había anunciado por carta mi próxima llegada. Campos me presentó al grupo de camaradas que, desde hacía algunos meses, venían publicando El Despertar ${ }^{24}$.

Campos debió de recibir con gran satisfacción la llegada de Adrián del Valle para reforzar, con su apoyo, su posición en El Despertar:

La ausencia de Luis Barcia, que había sido muy activo en la redacción del periódico y la falta de colaboración de J. C. Campos, motivada por incompatibilidades personales entre él y el compañero González ${ }^{25}$, que asumía la dirección, hacían que El Despertar se resintiera en su contenido. Desde mi llegada, colaboré en él y al poco tiempo reemplacé a González, que tuvo que ausentarse de la localidad ${ }^{26}$.

Esteve, por su parte, volvió clandestinamente a Barcelona a mediados de 1892. Pero la situación de persecución policial del anarquismo le complicó la vida. Con motivo del Primero de Mayo, el Gobierno Civil decretó el cierre de centros obreros, como la tipografía La Academia, que cerró en mayo de 1892, y Esteve se quedó sin trabajo. Ello, sumado a la crisis económica, con un fuerte aumento del desempleo, le hizo tomar la decisión de abandonar España y escogió Estados Unidos como destino porque allí se había establecido ya su muy querido amigo Adrián del Valle, junto a J. C. Campos, cuyas crónicas sobre los Mártires de Chicago tanto le habían impresionado. Esteve se fue a Francia en el mes de julio y se embarcó allí rumbo a Norteamérica. Así lo relata Adrián del Valle:

En las cartas que me escribía Esteve, ponía de manifiesto lo precario de su situación en Barcelona por la carencia de trabajo fijo. Contando con la promesa de Campos de que no le sería difícil trabajar en Nueva York en su oficio de tipógrafo, y con la solidaridad que pude yo ofrecerle, embarcó para Nueva York, estimo que sería a últimos del otoño o principios del invierno de $1892^{27}$.

\footnotetext{
24 Cultura Proletaria, 10-1927.

25 Manuel González, cubano, trabajó en El Productor de la Habana y colaboró en El Despertar de Brooklyn (véase, por ejemplo, 1-11-1891, "Carta a un patriota»). Manuel González y Marcelo Salinas se entrevistaron con Frank Fernández para su libro Anarquismo en Cuba (Madrid, Fundación Anselmo Lorenzo, 2000). El castrismo lo detuvo por militar en el anarquismo.

26 Cultura Proletaria, 10-1927.

27 Ibid.
} 
En realidad, fue en verano. El 8 de agosto de 1892, bajo el nombre de Pierre Esteve y a bordo del buque La Bourgogne, procedente de Le Havre, llegó al puerto de Nueva York, a Ellis Island, el centro de inmigrantes que acababa de inaugurarse ${ }^{28}$. Imaginamos que fue un viaje de al menos dos semanas. En las últimas décadas del siglo XIX, el transporte transoceánico se acortó en duración y se abarató en precio, lo que hizo posible a muchos obreros pagarse un billete de tercera clase. Los pasajeros de tercera, llamados también "pasajeros de entrepuente» (steerage, en inglés), eran hacinados cerca de las máquinas, donde se armaban cientos de literas (más de las reglamentarias porque los armadores procuraban incrementar al máximo la capacidad de carga) en condiciones de ventilación y salubridad pésimas. Estos inmigrantes de tercera necesitaban ser minuciosamente inspeccionados antes de permitirles la entrada en el país.

Bastantes años después, Esteve escribiría con el seudónimo de Lirio Rojo en su periódico de Nueva York Cultura Obrera una serie de artículos en los que rememoraba cómo había conseguido dinero de un amigo para el billete (probablemente Adrián del Valle) y que le obligaron a vacunarse en los muelles de Le Havre antes de embarcar. Tuvo que presentar a la oficialidad de a bordo la tarjeta en la que constaba que estaba vacunado y también ante las autoridades sanitarias, al llegar a la bahía de Nueva York. Sobre aquel viaje recuerda: «Para el que no lo sepa, en el buque nos habían dividido en pelotones de diez y dado cubiertos y platos de lata enmohecidos que debíamos nosotros mismos lavar para que, al sonar la campana, fuera uno en busca de la bazofia y el brebaje para todos ${ }^{29}$.

Recuerda también cómo se produjo su entrada en Estados Unidos, el supuesto paraíso. Vio la estatua de la libertad iluminando al mundo, pero no pudo poetizar, por más que se esforzó, según recordaba con sorna. En la isla de Ellis fue registrado y anotado cual si fuera un bulto:

Que ¿̨de dónde es y a dónde va?; y ¿̨cuánto dinero tiene?, y si viene contratado, y si es lisiado, o ladrón o anarquista, ¡qué entenderán por anarquistas estos

28 Pedro Esteve vivió en Estados Unidos desde 1892 hasta su muerte en 1925. Durante tres décadas tuvo allí una actividad frenética e ininterrumpida, realizó un inmenso trabajo de agitación y propaganda de las ideas anarquistas entre los medios obreros españoles, italianos y cubanos. En Nueva York, en Paterson (New Jersey), en Tampa (Florida), en los campos mineros del oeste, entre los obreros textiles, los tabaqueros, los mineros, los trabajadores del mar y de los muelles, fue la figura libertaria española más influyente. Casanovas (1992) y Sueiro (2013).

29 «Remembranzas. La Gran República», Cultura Obrera, 18-11-1911, p. 2. 
bárbaros enguantados y con zapatos! Había yo entrado y salido de Italia, de Francia, de Bélgica, de Inglaterra, sin que jamás se entrometiera, al menos públicamente, en mis asuntos nadie, y para entrar en New York se me exigía una confesión general ${ }^{30}$.

Esteve no sabía inglés, llevaba poco dinero y sus dos amigos, Campos y Adrián del Valle, no habían ido a buscarle a Battery Park. Escribió «un par de postales para que vinieran enseguida a desfacturarme». Sobre su llegada a la redacción de El Despertar dice, años después:

Cuando vine a Nueva York, me encontré con un grupo ya constituido, el Parsons, que publicaba el quincenal El Despertar. [...] Formaban parte de él las mayores capacidades del elemento anarquista de habla española residente en los Estados Unidos: Campos, Adrián del Valle, Luis Barcia y lo mejorcito del elemento entre tabaqueros. Es más, puede decirse que era un grupo de oficio también, pues llegamos a pasar de la cincuentena (tal vez ha sido el grupo más numeroso que ha existido) y solo tres no éramos tabaqueros ${ }^{31}$.

Con el impulso de Esteve, la redacción del periódico contó con una Biblioteca de El Despertar que publicó y distribuyó muchos folletos y libros. Además, el grupo inauguró, el 1 de abril de 1893, un círculo anarquista en Brooklyn. El Despertar daba cuenta de la velada celebrada con ese motivo hasta las tres de la madrugada y hacía notar que, a pesar de lo reducido de la colonia hispanohablante en Estados Unidos en comparación con la alemana, la rusa o la italiana, los anarquistas que hablaban español eran muy activos, como demostraba el hecho de que publicaban un quincenario anarquista, existían diversos grupos ya constituidos y acababa de constituirse el círculo ${ }^{32}$.

En aquellos tiempos — seguía recordando Esteve- la colonia española era diminuta y, sin embargo, llegamos a publicar El Despertar semanalmente (gracias a que, cada uno del grupo, contribuía con su parte alícuota para los gastos del periódico, que no eran muchos porque no costaba ni un centavo la redacción y administración y poco su impresión, por ser muy corto el tiraje); pero tanto en el periódico como fuera de él, de lo que nos preocupábamos era de hacer sentir nuestra influencia fuera del grupo, ya dentro de la sociedad de resistencia de tabaqueros, como en el Círculo de Trabajadores por nosotros creado.

$30 \quad$ Ibid.

31 «IX. El revisionismo», Cultura Obrera, 15-11-1924.

32 «Nuestra velada», El Despertar, 1-5-1893. 


\section{PEDRO ESTEVE, FIGURA CLAVE}

Así recuerda Adrián del Valle lo que Esteve supuso para el periódico de Brooklyn:

Dado el carácter dinámico de Esteve, y la fama de que ya gozaba entre sus compañeros, su llegada dio motivo a una intensificación de la propaganda entre la colonia de habla hispana y a una mayor relación con los compañeros de las demás colonias extranjeras, particularmente la italiana.

Con él, el grupo Parsons, editor de El Despertar, engrosó notablemente, volvió a colaborar en el periódico Campos, se celebraron conferencias y veladas y se editaron algunos folletos. Fue un periodo de actividad y entusiasmo, y es innegable que a su manifestación contribuyó en gran manera Pedro Esteve con su dinamismo y espíritu de iniciativa ${ }^{33}$.

El Despertar alcanzó por entonces un carácter decididamente transnacional. Díaz del Moral recordaba que se recibía regularmente en Andalucía, en un fructífero intercambio de publicaciones anarquistas ${ }^{34}$. Por su parte, la italiana Maria Roda, la compañera de Esteve, en un artículo al cumplirse un año de su fallecimiento, afirmaba:

"El Despertar vivió muchos años, colaborando en él las mejores plumas anarquistas de aquel tiempo, y seguramente Esteve es donde ha puesto todas sus energías, sus sueños idealísticos (sic), todo el entusiasmo que lleva en sí la juventud ${ }^{35}$.

Por su parte, Del Valle, al recordar en los años veinte a su amigo desaparecido, aseguraba:

«Hasta febrero de 1895 la redacción de El Despertar estuvo principalmente a mi cargo. Habiendo decidido irme a Cuba, Esteve ocupó mi lugar en el periódico y en él permaneció hasta que cesó de publicarse años después $\aleph^{36}$.

Desde su llegada a Nueva York, Del Valle perteneció a la redacción de $E l$ Despertar y en algún momento se hizo cargo de la dirección. Publicó, bien firmando como Palmiro, bien como Adrián del Valle, sus colaboraciones,

\footnotetext{
«Pedro Esteve», Cultura Proletaria, 10-9-1927.

Díaz del Moral (1967): 127 y 138.

Cultura Obrera, 11-9-1926.

36 «Pedro Esteve», Cultura Proletaria, 10-9-1927.
} 
siempre muy literarias ${ }^{37}$. Sin embargo, es muy probable que mucho antes de irse Del Valle a Cuba, Esteve ya ocupara en el periódico un lugar central. Su compañera, en el artículo de recuerdo citado, dice que Esteve "salió de España, por razones que no es del caso hablar ${ }^{38}$, en 1892, vino a Estados Unidos y empezó aquí su actividad, junto con Palmiro de Lidia y un viejo compañero cubano llamado J. Campos» ${ }^{39}$. El historiador anarquista Vladimiro Muñoz (1920-2004) afirma que, cuando El Despertar publicó como folletín el ensayo de Ricardo Mella La coacción moral, en 1893, era «una publicación dirigida en Brooklyn (Nueva York) por el anarquista barcelonés Pedro Esteve» ${ }^{40}$.

Toda la energía que había puesto en el periódico de su ciudad natal, la puso en el periódico de Brooklyn, que trasladó su sede al 242 de Pearl St. y luego a 124 Fulton St., su domicilio.

Frente a los anarquistas contrarios a los congresos, Pedro Esteve los consideraba fundamentales para que el movimiento avanzase:

«porque avivan la inteligencia, son vínculo de fraternidad, estimulan la creación de nuevos núcleos de propagandistas; promueven discusiones en los grupos y en los periódicos, hacen que surjan ideas y propósitos, aúnan voluntades y, contrastando costumbres e ideas, teorías y hechos, hipótesis y axiomas, purifican y embellecen nuestros principios ${ }^{41}$.

Además, de ellos podían salir acuerdos prácticos de acción. Abogó por la celebración de uno en Chicago mientras estuviese abierta allí la Exposición Universal $^{42}$. Era necesario - afirmaba - que los anarquistas intercambiasen impresiones y pusieran en común las diversas ideas sobre organización, táctica y propaganda de los distintos grupos y regiones, "con vistas quizás a una

37 El primer texto que publicó Del Valle en El Despertar se tituló «Las leyes», en el número de 1. ${ }^{\circ}$ de marzo de 1892, con la firma de Palmiro. El 15 de mayo de 1892 dedica su colaboración "A mi queridísimo amigo P. E.» (Pedro Esteve): "A nadie mejor que a ti pudiera dedicar este escrito, que fuiste el primero en leer. Recibe pues esta dedicatoria como una prueba de amistad que desde tierras americanas te envía tu cariñoso amigo".

38 Parece insinuar que se fue porque se sentía perseguido por lo de Jerez, como en parte así fue.

39 «[...] fundando un periódico que, si mal no recuerdo, se llamaba El Esclavo (sic)». Se equivoca, lo que no es de extrañar, ya que en aquel periódico de Tampa también tuvo Esteve, algo después, un papel muy destacado.

40 Muñoz (1974): 102.

41 "Conferencia anarquista (II)», El Despertar, 15-2-1893, p. 1.

42 «Conferencia anarquista (I)», El Despertar, 1-2-1893, p. 1. 
común inteligencia» y para conseguir «la unidad de acción revolucionaria, tan necesaria para combatir un enemigo fuerte y poderoso como es la burguesía ${ }^{43}$. En España, la publicación hermana, El Productor de Barcelona, promovió la participación en dicho congreso e hizo una suscripción y un escrutinio para designar al candidato que viajase a Chicago en representación de los anarquistas espańoles. Se recaudaron 1185,45 pesetas. Se publicaron los votos obtenidos por los candidatos y, aunque solo aparecían las iniciales de sus nombres, es fácil distinguir a las figuras más relevantes del anarquismo español del momento ${ }^{44}$. A pesar de los esfuerzos del periódico barcelonés, lo recaudado era insuficiente, así que se optó por la delegación indirecta, «encargando la representación a los compañeros P. Esteve, J. C. Campos, Palmiro, por el orden que se citan, residentes en Nueva York, por si sucediese que alguno de estos compañeros no pudiese, por cualquier circunstancia, cumplimentar nuestro deseo» ${ }^{45}$.

Finalmente, fue Pedro Esteve quien acudió como representante de España y Cuba. No estuvo presente nadie que no residiera en Estados Unidos, de modo que Esteve consideró más ajustado hablar de conferencia y no de congreso. Escribió una larga memoria de lo discutido, que se publicó por entregas en El Despertar a lo largo de 1894.

Mientras, en Brooklyn, Esteve infundía brío a El Despertar, con gran pesar recibió la noticia de la desaparición de El Productor de Barcelona ${ }^{46}$.

Uno de los rasgos de la impronta de Esteve en El Despertar fue su estrecha relación con el mundo inmigrante italiano. Al llegar a Estados Unidos, por indicación de una de las figuras más importantes del anarquismo internacional, Errico Malatesta, con quien ya había tenido estrecha relación antes de viajar a Estados Unidos ${ }^{47}$, Esteve fue a Paterson, New Jersey, a 17 millas de distancia al

43 «Saludo», El Despertar, 1-10-1893.

44 Con mucho, quien aparecía con más votos, 1208, era R. M. (Ricardo Mella); a continuación F. T. (Fernando Tarrida), con 780; luego J. L. M. (José López Montenegro), con 525, y en cuarto lugar aparecía P. E., esto es, Pedro Esteve, con 256. A más distancia quedaban otros, como J. Ll. (Josep Llunas), con 91; A. L. (Anselmo Lorenzo) con 91, o V. G. (Vicente García), con 8.

45 El Productor, 17-8-1893, p. 1,

46 «Siete años hacía que venía luchando con tesón y bravura», aseguraba. Tras la represión consiguiente al levantamiento anarquista de Jerez, la imprenta se negó a seguir editándolo y fueron inútiles cuantas gestiones se hicieron para encontrar otra imprenta que quisiera hacerse cargo del periódico. El último número fue de 21 de septiembre de 1893. El Despertar, 1-12-1893, p.1.

47 Las comunicaciones de Esteve, en Nueva York, con Malatesta, que residía en Londres, aunque fluidas, eran a veces muy difíciles porque las cartas eran interceptadas por la policía. Esteve se valió de El Despertar para hacerle llegar información a través 
oeste de Manhattan, una ciudad muy anarquista, que era conocida como «la ciudad de la seda» por las múltiples fábricas de tejidos de seda en las que trabajaban inmigrantes. Allí conoció a la obrera anarquista italiana María Roda, que se convirtió en su compañera de por vida. Se sintió muy cómodo entre los anarquistas italianos que editaban $L a$ Questione Sociale y, de hecho, durante un tiempo, fue él el director de este periódico de Paterson escrito en italiano.

También se notó que era Esteve quien imprimía carácter a El Despertar en el tratamiento de la cuestión de la emancipación cubana ${ }^{48}$. Llevó a cabo una estancia en Cuba en 1893-94 para dar a conocer lo discutido en Chicago. Allí estableció fuertes lazos de amistad y camaradería, y en La Habana editó La Alarma (que, al ser prohibido, pasó a llamarse Archivo Social), pero ante la persecución policial que emprendieron contra él las autoridades coloniales de Cuba, tuvo que escapar de la isla y buscó entonces refugio en Tampa, Florida. Lo primero que hizo Esteve en Tampa, como hacía siempre que llegaba a un nuevo lugar, fue fundar, con amigos como Luis Barcia, un periódico, El Esclavo, que se publicó entre 1894 y 1898, y fue muy leído, no solo en Florida y en Cuba, sino que se recibía regularmente en Buenos Aires, así como en España, a través del canje de publicaciones. El intercambio entre El Esclavo de Tampa y El Despertar de Nueva York fue constante: se enviaban a sus respectivas redacciones paquetes con los números atrasados, para estar al tanto de lo que cada uno publicaba.

La divergencia de una parte del equipo editorial de El Despertar con la opinión de Esteve sobre la cuestión cubana decidió a los disconformes a fundar en 1898 otro periódico en Brooklyn, El Rebelde, redactado por Adrián del Valle - que regresó pronto a Nueva York al sentirse inseguro en Cubajunto con Luis Barcia, J. C. Campos y Gerardo Quintana. Así lo recordaba Adrián del Valle,

En El Esclavo de Tampa, el antiguo y excelente camarada Luis Barcia mantenía el criterio de apoyar a la causa nacionalista cubana, que yo compartía, en oposición a la actitud de indiferencia ante la Revolución cubana asumida por El Despertar. No pretendo discutir cuál de las dos tácticas era la más justificada. Constato escuetamente los hechos. Desde luego, tengo la convicción de que, al defender la segunda, lo hacía Esteve convencido de que era la que estaba más en armonía con el ideal, y con igual convicción defendíamos nosotros la primera.

de una sección titulada «Entre nos», que le servía para mandar avisos o dar acuse de recibo de una carta, de un paquete, de un envío de periódicos o de colectas para contribuir a alguna causa.

48 Sueiro (2018): 97-120. 
Los que habíamos adoptado la táctica simpatizadora, publicamos a mediados de 1898 El Rebelde, del que aparecieron cuatro números. Editamos también un vibrante manifiesto, al terminarse la guerra hispanoamericana, excitando al pueblo espańol a la revolución. Los principales redactores de $E l$ Rebelde fuimos Campos y yo. En diciembre de 1898, volví a Cuba. Desde aquel entonces, dejé de ver a Esteve, que continuó siendo el alma de El Despertar hasta que dejó de publicarse ${ }^{49}$.

Cuando sus antiguos colegas publicaron en Brooklyn El Rebelde, Esteve se fue con El Despertar a Paterson, al mismo taller donde editaba La Questione Sociale, en el 353 de Market St., hasta el final de la publicación en 1902 ${ }^{50}$, una prueba más de hasta qué punto el periódico había llegado a ser su obra personal.

\section{LOS ASUNTOS DE ESPAÑA Y LA «PROPAGANDA POR EL HECHO»}

El Despertar dio mucha información sobre la situación política y el movimiento obrero en España. Sabemos — aunque la identificación no es fácilque el corresponsal para asuntos de España era Vicente García y García (1866-1930) $)^{51}$, que ya antes de la llegada de Esteve a Nueva York mandaba sin nombre sus crónicas desde Bilbao, firmando como «El corresponsal» y despidiéndose siempre con la consabida «Salud y pronta Revolución Social $»^{52}$.

49 «Pedro Esteve», Cultura Proletaria, 10-9-1927.

50 La redacción y el taller de imprenta estaban en Paterson, aunque la administración, según la cabecera del periódico, seguía en el 226 de Fulton St., de Brooklyn, NY.

51 Vicente García había nacido en la pequeña aldea de Para-la-Cuesta, Burgos, en el seno de una mísera familia de campesinos castellanos. A los 12 años se trasladó a Bilbao, a casa de su hermano mayor, y allí entró en contacto con el anarquismo. Impulsó una escuela laica en Sestao en 1889-1890. En 1890 publicó en San Sebastián El Combate, cuyo primer número fue denunciado y le valió una condena de tres meses de cárcel. De acuerdo con Esteve, su periódico abanderó la evolución del colectivismo al anarcocomunismo. En el País Vasco destacó, tanto en la primera jornada reivindicativa del Primero de Mayo, en 1890, como en la primera gran huelga minera. En 1891 volvió a editar El Combate, ahora en Bilbao, del que salieron tres números. Luego publicó en Haro Justicia Obrera. Fue tal la inquina de la clase patronal de La Rioja, por haber organizado a los obreros de la comarca, que le negaron el trabajo, a pesar de que su oficio de tonelero era muy demandado.

52 Sabemos con toda seguridad que es Vicente García porque habla de que «en esta villa» se va a publicar en breve El Combate «ya que la persecución autoritaria hizo que solo se publicase un número en San Sebastián». Envía el 28 de mayo de 1891 una 
Durante la gira de propaganda por España realizada por Esteve y Malatesta en 1891-92, fue García quien los acompañó durante su estancia en el País Vasco y Santander, y les presentó en los mítines, en los que hubo mucha discusión y controversia ${ }^{53}$. García se sintió muy comprometido ya que, a raíz de la fracasada sublevación anarquista de Jerez, huyó a Inglaterra para eludir la represión, al igual que Esteve y Adrián del Valle.

En El Despertar son reiteradas sus correspondencias a propósito de la situación en Andalucía. Tras las primeras noticias de los sucesos de Jerez conocidas por la prensa burguesa, los anarquistas hispanohablantes de Nueva York tuvieron que esperar a recibir la crónica de Vicente García para conocer mejor los hechos. Aunque muchos compañeros juzgaron la revuelta precipitada y mal organizada, él la justificaba como un desahogo espontáneo, irreprimible e impaciente de los campesinos oprimidos, que protestaban contra la injusticia y el hambre; eran motines y levantamientos, no solo inevitables, sino necesarios para el advenimiento de la revolución social. Lo mismo señalaba Luis Barcia:

Esas revueltas, esos asaltos y esas matanzas son los arroyos y los manantiales que están formando el gran río de la Revolución que, en no lejano día, ha de arrollar, desbordándose, privilegios, explotaciones, injusticias y tiranías; todo lo que se oponga a la majestuosa y niveladora marcha de su corriente. Para que ese dichoso momento llegue cuanto antes, los anarquistas debemos organizarnos para la conspiración y desplegar toda nuestra actividad y energía ${ }^{54}$.

Cuando el 10 de febrero de 1892 fueron ajusticiados a garrote vil cuatro de los anarquistas de Jerez, en El Despertar se hizo una suscripción de ayuda a sus familias, se nombró una comisión recaudadora que fue por los diferentes talleres de tabaquería, no solo de Nueva York sino también de Florida, Boston y Toronto (Canadá), y se publicaron las listas de lo recaudado, encabezadas por lo donado por el propio periódico. Las sumas se giraron al administrador

carta contando cómo se celebró en «esta región llamada España» la jornada del Primero de Mayo y dice que mandó, estando en la cárcel, una correspondencia anterior que no llegó y, por tanto, no se pudo publicar, según él porque «unas ratas» la atraparon y la requisaron en correos (El Despertar, 1-6-1891).

53 En Bilbao no se pudo celebrar el mitin porque no se encontró local, por no querer ningún dueño alquilar sus salones para reuniones anarquistas, pero sí los hubo en Sestao y en la localidad minera de Ortuella. La siguiente parada de Esteve y Malatesta, acompañados de Vicente García, fue Santander.

54 «Importante», El Despertar, 15-3-1892. 
de El Productor de Barcelona, que lo repartió entre las familias de los agarrotados en Jerez de la Frontera.

La corresponsalía de Vicente García al relatar las ejecuciones es muy violenta. Dice que la revolución social se aproxima «a pasos de gigante» y que no quedará con vida «ninguno con uniforme, de cabo para arriba». Se compadece de la desesperación e incultura de unos campesinos que se rebelan solo con palos y piedras, "cuando la ciencia ha puesto al alcance del anarquista otros medios de defensa»:

Más valía que se emplease el dinero en folletos explicando la química ${ }^{55}$, diosa que resolverá el problema social, porque los privilegiados no cederán nunca hasta que no hagamos polvo sus cráneos, y si a todos los obreros se les hubiera provisto de estos folletos, los compañeros de Jerez no hubieran empleado los palos y las piedras.

La temible dinamita es el arma más barata, por lo que el obrero puede adquirirla con facilidad. Si algunos aconsejan a los obreros la fabricación de dinamita es con objeto de que la empleen cuando llegue el momento oportuno, esto es: la Revolución ${ }^{56}$.

El Despertar defendió el recurso a la violencia desde el mismo momento de su fundación. Abogó por la llamada "propaganda por el hecho», esto es, el uso selectivo de la fuerza como medio eficaz para acelerar el cambio revolucionario, al excitar el ardor de los obreros y hacer caer el mito de la invencibilidad de la burguesía ${ }^{57}$. El anarquista de acción daba un gran ejemplo de sacrificio y abnegación al ofrecer su vida por la causa. Los autores de los atentados se convertían en mártires, especialmente los magnicidas, lo que contribuía a que

55 La "química» era, para los anarquistas, sinónimo de ciencia para fabricar dinamita. Desde la prensa se urgió al anarquista al estudio de los avances de la química para aprender el uso de explosivos. De forma general, se consideró que había que aprovechar el gran potencial revolucionario de la dinamita, inventada por el empresario y científico sueco Alfred Nobel, que «hizo, sin desearlo, una contribución fundamental al ascenso del terrorismo anarquista, inventando la primera arma de destrucción masiva, fácilmente disponible para los miembros enérgicos de las clases oprimidas en casi todo el mundo" (Anderson, 2008, 60). Un arma temible, efectiva y barata, que los obreros podían fabricar o adquirir con facilidad. Un maravilloso regalo que la ciencia les había hecho.

56 El Despertar, 1-3-1892, por El corresponsal.

57 Esta táctica fue aprobada en el congreso anarquista internacional de Londres de 1881 y adoptada entre los anarquistas de Estados Unidos en el manifiesto del Congreso de Pittsburgh de 1883. 
surgieran emuladores dispuestos a vengar sus muertes. En El Despertar, este discurso fue fundamentalmente debido a la pluma de J. C. Campos, que distinguía entre los hombres de ideas, inteligencias excepcionales, como Proudhon, Bakounine, ó Kropotkhine, y

los hombres de temperamento ardiente, que se enamoran de la idea como un galán de su dama, y a estos últimos les toca llevar a la práctica lo que los primeros concibieron. ¡Los unos son el cerebro, los otros el corazón, el brazo! Hombres a quienes no preocupan el odio de los tiranos, ni los calabozos ni la horca, hombres para quienes las persecuciones son un incentivo. Hombres como Spies, que pocas horas antes de subir al patíbulo, escribe a su madre y le dice: «Cuando yo muera, no llores, no te apesadumbres, porque son pocos, muy pocos, los hombres a quienes, como a mí, les cabe la gloria de morir por defender la libertad $\|^{58}$.

El Despertar dedicará mucho espacio, y el más destacado, en primera página, a homenajear a los mártires del movimiento, empezando por los de Chicago, el 11 de noviembre de cada año ${ }^{59}$. El periódico dejaba hablar a los propios mártires. Se recordaban sus discursos pronunciados ante el tribunal que les había condenado a muerte, así como sus últimas palabras antes de subir al patíbulo, mostrando a unos hombres gallardos, orgullosos, dispuestos a morir con gran dignidad por sus ideas. Las palabras de Luis Lingg no dejaban lugar a dudas sobre los medios que los anarquistas, a los que El Despertar honraba, estaban dispuestos a usar:

Declaro otra vez, franca y abiertamente, que soy partidario de los medios de fuerza. Si vosotros empleáis contra nosotros vuestros fusiles y vuestros cañones, nosotros emplearemos contra vosotros la dinamita. Os reís probablemente porque estaréis pensando: «ya no arrojarás más bombas». Pues permitidme que os asegure que muero feliz porque estoy seguro de que los centenares de miles de obreros a quienes he hablado recordarán mis palabras y, cuando hayamos sido ahorcados, ellos harán estallar las bombas. En esta esperanza os digo: os desprecio, desprecio vuestro orden, vuestras leyes, vuestra fuerza, vuestra autoridad. jAhorcadme ${ }^{160}$.

Parsons por su parte, según El Despertar, había hecho la siguiente reflexión durante las ocho horas que habló ante el tribunal:

58 «Soy anarquista», El Despertar, 1-7-1891, p. 1.

59 El lenguaje utilizado para recordarlos es totalmente religioso, donde abundan las referencias al sacrificio, la inmolación, la redención y también a la necesidad de venganza.

60 El Despertar, 1-11-1891. 
La policía está armada con los modernos fusiles Winchester y las organizaciones obreras carecen por completo de medios de defensa. Uno de aquellos fusiles cuesta dieciocho duros y nosotros no podemos comprarlos a semejante precio. ¿Qué deben hacer los trabajadores? Una bomba de dinamita cuesta treinta céntimos y puede ser preparada por cualquiera. [...] hoy la dinamita es el medio de emancipación popular.

Por supuesto, la violencia que defendían se justificaba como contraviolencia frente a un Estado despótico y opresor y un capitalismo injusto y despiadado, como se había encargado de puntualizar Schwab, otro de los Mártires de Chicago: «Es un error emplear la palabra "anarquía» como sinónimo de violencia pues son cosas opuestas... Nosotros propagamos la violencia, pero solamente contra la violencia, como medio necesario de defensa».

El mismo ańo -1892- en que Esteve emigró a Estados Unidos, comenzó la época de los magnicidios. Los años de El Despertar, la última década del siglo xix, fue el periodo en que más monarcas, presidentes y primeros ministros fueron asesinados de toda la historia ${ }^{61}$. En Francia, destacaron las acciones de Ravachol, Vaillant y Henry ${ }^{62}$. En España, el primer acto de propaganda por el hecho propiamente dicho fue el de Paulino Pallás, siete meses después de las ejecuciones de Jerez. Pallás había nacido en Tarragona y emigrado de joven con sus padres a la Argentina, donde trabajó como aprendiz de tipógrafo y se hizo anarquista. El 24 de septiembre de 1893 arrojó en Barcelona unas bombas durante un desfile militar con motivo de las fiestas de la Merced con la intención de asesinar al capitán general de Cataluña, el general Martínez Campos, que salió ileso, aunque el atentado provocó un muerto y varios heridos. Tras su acto, no pensó en escapar, lanzó su gorra al aire gritando: «iViva la anarquía!», y fue detenido sin oponer resistencia. Aceptaba que su acción le llevaría al cadalso. Se comportó de forma impecable, según el modelo anarquista. En el momento de ser fusilado en el patio del castillo de Montjuich, rehusó consuelo religioso y murió con gran entereza entonando un himno anarquista. Creía estar haciendo un gran servicio a la humanidad al atentar contra un representante del Estado y del Ejército, y su único pesar, según dijo en el juicio, era no haberlo consumado. Cuando la policía registró su casa, aparte de periódicos anarquistas, encontró un ejemplar de La conquista del pan de Kropotkin y una litografía de los Mártires de Chicago.

El «atentado de la Gran Vía», como se conoció en la época, tuvo gran repercusión en la conferencia anarquista de Chicago de ese año, donde se

${ }^{61}$ Jensen (2006).

62 Maitron (1975) y Sonn (1989). 
consideró su acción justificada por los terribles actos cometidos por el Estado español, también en sus colonias. J. C. Campos firmaba en El Despertar un artículo particularmente violento titulado "A Pallás me atengo»:

No hay compasión para nosotros. Morimos extenuados por el hambre y agobiados por un trabajo ímprobo y sin recompensa, y del mismo modo sucumben nuestros hijos. ¡Qué mueran, pues, nuestros verdugos y sus hijos atravesados por el plomo! ¡Qué no haya compromiso! ¡Qué tampoco haya de nuestra parte compasión! Para desatar las ligaduras que nos oprimen es indispensable emplear la fuerza [...]. Nos hemos propuesto enseñar a los burgueses que, si a hierro matan, a hierro deben morir. Y por eso es que yo, a Pallás me atengo. [...] ¿Medios pacíficos cuando vemos que, a la menor protesta de los trabajadores, contestan los tiranos con la metralla y el patíbulo? [...] ¡Al veneno y al plomo que nos ofrecen los burgueses, debemos los trabajadores oponer la daga y la dinamita! ¡A un golpe otro golpe! $\mathrm{Y}$ pues que no hay otro camino, es por esto que yo, ¡a Pallás me atengo! ${ }^{63}$.

El Despertar llevó a cabo una campaña para recaudar fondos para sostener a la viuda e hijos de Pallás. En abril de 1894 se le habían mandado 1025 pesetas ${ }^{64}$.

Solo unas semanas después del ajusticiamiento de Pallás, la noche del 7 de noviembre de 1893, durante la representación del segundo acto de la ópera Guillermo Tell en el Liceo, el teatro de la ópera de Barcelona, otro anarquista, Santiago Salvador, arrojó al patio de butacas desde el quinto piso dos bombas Orsini. Solo una de ellas estalló y mató a veinte personas, dejando heridas a otras veintisiete. Declaró que había actuado para vengar a Pallás y fue ejecutado a garrote vil el día 24. El Despertar creía que, a pesar de su conducta errática $^{65}$, su acto había servido mucho al ideal:

63 El Despertar, 10-9-1894, p. 1.

64 «Importante», El Despertar, 1-4-1894. La suscripción comenzó con la contribución de un dólar por parte de los principales redactores del periódico: Pedro Esteve, Adrián del Valle, José Campos, y otro de la mujer de este, Isabel Durio. Dos meses después, El Despertar publicaba una carta de la viuda de Pallás, Ángela Vallés, anunciando el nacimiento de su hijo póstumo, de quien, decía, "espero que imite a su padre y vengue el crimen de la burguesía», agradeciendo las 1025 pesetas que le habían enviado. El Despertar, 1-6-1894, p. 4., citado por Moya (2010): 531.

65 El Despertar no tenía hacia Salvador la misma incondicionalidad que hacia Pallás. Ello era debido a su debilidad de carácter, nada ejemplar por su supuesto arrepentimiento y conversión al catolicismo (antes de anarquista había sido carlista). Según el periódico, Salvador no tuvo la actitud adecuada esperable en un buen 
Las bombas del Liceo fueron una advertencia que no será fácilmente olvidada. Significose que no podían considerarse inocentes, y por tanto vivir tranquilos, los que pretenden ser inofensivos y son los únicos causantes del malestar social. El mundo es como una vasta Plaza de Toros. Sirven de toros y caballos los trabajadores, de toreros las autoridades civiles y eclesiásticas y de público los capitalistas. ¿Quiénes son los culpables de que el sanguinario espectáculo se realice? ¿Los toros y caballos que por la fuerza bregan en la arena, los que ejercen de toreros por lo que les pagan, o el bárbaro público que aplaude o protesta según le parezcan las suertes? Nosotros creemos que el público y cuántos en la apertura de la temporada de ópera se sientan en las muelles butacas de la platea del Liceo, así como en los palcos del primer, segundo y tercer piso y aún en los asientos fijos del cuarto, son ese público burgués que aplaudía desde los balcones de sus casas la proclamación del estado de sitio cuando las huelgas del $10^{\circ}$ de Mayo, y se refocila viendo los buques de guerra convertidos en terribles cárceles para los trabajadores, por no caber ya los arrestados en las prisiones ni en las fortalezas; que excitan a los legisladores a que promulguen leyes contra el obrero y azuzan a las autoridades para que peguen duro y sin guardar contemplaciones, que reprochan e insultan a los trabajadores cuando se rebelan contra la tiranía y el despojo [... $]^{66}$.

El Despertar daba mucha información sobre los últimos momentos de Salvador, al que se dedicaba prácticamente un número entero ${ }^{67}$, y acababa con toda una declaración a favor de la propaganda por el hecho:

anarquista y ahí se apartó de todos los demás mártires «de temple durísimo y límpido» que «desde Ravachol a Caserio, como antes los Mártires de Chicago», «encargáronse ellos mismos, todos, de justificar su conducta y de defender el ideal que les impulsó». «Santiago Salvador Franch», El Despertar, 30-11-1894, p. 1.

67 Se relata con detalle, no solo la ejecución, sino las horas previas. Asegura que, al retractarse y decirse arrepentido, había representado una farsa, combatiendo a la burguesía con sus mismas armas, la mentira y la astucia. De ese modo, había logrado que le tratasen bien en la cárcel, había conseguido comer, beber y dormir bien. Llega el momento, a las 7:30 el verdugo procede a la tarea de «vestir al reo con una hopa negra y un gorro del mismo color, quitándole los grilletes y las esposas [...]. Salvador subió con ligereza y sin ayuda de nadie las escaleras del cadalso y al llegar a la plataforma gritó: «Viva la Revolución Social, Viva la Anarquía, mueran las Religiones Todas». Dirigiéndose al verdugo le dijo: "Apodérate de mi cuello y acaba pronto». Mientras el ejecutor hacía su cometido, Salvador cantó el himno anarquista concluyendo con la estrofa que dice: "Antes que esclavo prefiero morir». Pocos segundos después Santiago Salvador Franch era cadáver». 
Según la prensa burguesa, cumpliose la justicia humana. Según nosotros, se satisfizo la venganza burguesa. Una diferencia de apreciación que puede llevarnos muy lejos a unos y otros. A nosotros, los anarquistas, podrá llevarnos al cadalso, pero a ellos, a los burgueses, los llevará a ser pasto de los dinamiteros. Aunque somos ateos, rendimos culto en estos días de lucha y de venganza, al único dios que ha de redimirnos: la fuerza. ¡Loor, pues, a sus más fervientes adoradores, los dinamiteros! $!^{68}$.

Pocos días antes del atentado de Pallás, en septiembre de 1893, Malatesta informaba a un correligionario de Milán que se habían enviado instrucciones a España para fabricar explosivos ${ }^{69}$. Pallás había conocido a Malatesta en Buenos Aires y con él hizo un viaje a la Patagonia. Celebró el Primero de Mayo de 1890 en Rosario, donde por entonces residía el anarquista italiano Francesco Momo. Estuvo luego en Brasil, donde arrojó un petardo en un lujoso teatro de Río de Janeiro durante la conmemoración del Primero de Mayo de 1892, y de allí volvió a Barcelona con su mujer y sus tres hijos. En Barcelona es probable que se encontrara con Malatesta (y también con Esteve, antes de abandonar éste España rumbo a Nueva York). Sin duda se encontró con Francesco $\mathrm{Momo}^{70}$, que fue quien le proporcionó las bombas Orsini.

En noviembre de 1893, un agente secreto infiltrado en los medios anarquistas de Ginebra, informaba a la policía parisina de que las bombas de Barcelona, tanto contra Martínez Campos como las arrojadas por Santiago Salvador en el Liceo, habían sido fabricadas por un italiano que había muerto al preparar explosivos, aunque le había dado tiempo a dejar escondidas un buen número de ellas. Esta versión coincide con lo declarado en el juicio por el propio Pallás sobre quién le había proporcionado las bombas. En efecto, Francesco Momo murió el 13 de marzo de 1893 mientras fabricaba en su taller de San Martín de Provençals (Barcelona) una de esas bombas Orsini, pero había dejado en lugar seguro un lote listo para ser utilizado. Pallás usó alguna de ellas, como también las usó Santiago Salvador en su atentado del Liceo de Barcelona, y se usaron también en el atentado de Cambios Nuevos. Nada menos que tres atentados se realizaron con el mismo lote ${ }^{71}$.

68 El Despertar, 1-12-1894.

69 Avilés (2006): 23.

70 Momo estuvo en la Argentina en 1885 y viajó a Barcelona en 1892, junto con varios compañeros catalanes que había conocido en Argentina donde, al igual que en Estados Unidos, los anarquistas italianos y españoles se relacionaban intensamente, y mantuvieron esos vínculos una vez regresaron a Europa.

71 Moya (2010): 366, y Jensen (2014). 
La corriente partidaria de actos de "propaganda por el hecho» se caracterizó por su carácter transnacional y por una estructura organizativa muy flexible y descentralizada, basada en pequeños grupos de acción ligeros, móviles y laxamente interrelacionados. Las decisiones sobre un atentado las tomaban unas pocas personas relevantes, muy relacionadas entre sí, aunque de forma secreta $^{72}$. Los grupos anarquistas compuestos por exiliados en París y en Londres jugaron un gran papel, como también, y esto es prácticamente desconocido, los grupos de habla hispana e italiana de Estados Unidos. Entre estos últimos, desempeñó un papel central Pedro Esteve, el anarquista español más interconectado, que en la época de El Productor de Barcelona, muy influido por Campos y luego también por Malatesta, había experimentado un giro hacia la vía secreta e ilegal y los métodos de la «propaganda por el hecho». El 20 de junio de 1894, Esteve, desde la primera página de El Despertar, corregía al semanario librepensador Las Dominicales del Libre Pensamiento, de Madrid, que se había permitido augurar, interpretando erróneamente un artículo de Malatesta, que los anarquistas estaban a punto de desterrar el uso de explosivos como arma de combate:

El anarquismo no realiza la evolución que Las Dominicales supone. Por el contrario, los acontecimientos le impelen cada día más a considerar como grande y bella arma los explosivos y aun el usarlos con más frecuencia de la que el humanismo reclama. Su empleo no ha sido nunca, y menos ahora, producto de la calentura o la fiebre, y sí resultante del frío raciocinio. Ravachol, Pallás, Vaillant y Henry han probado, justificado con sus palabras y sus hechos, que no eran hombres que la pasión les enloqueciera y realizaran hechos que en estado de calma tuvieran que arrepentirse, y sí de los que, antes de obrar, meditan bien lo que van a hacer. Además, ni Malatesta, ni Reclús, ni nosotros, ni ningún anarquista consecuente, puede rechazar el empleo de explosivos como medio de defensa y propaganda [...]. ¿Qué anarquista pensará en

72 El propio Bakunin creía necesarios pequeños grupos clandestinos que impulsaran y dirigieran la revolución. Kelly (1987), citado por Avilés (2012): 227-249. A una hermandad secreta fundada por él, de la que formaban parte los italianos Carlo Cafiero y Errico Malatesta, se incorporó más tarde el exiliado ruso Piotr Kropotkin, quien en 1881, en vísperas del Congreso Revolucionario Internacional que se celebró en Londres, les propuso una doble estructura: «Yo creo que nos hacen falta dos organizaciones. Una abierta, amplia, que funcione a la luz del día; otra secreta, de acción. La abierta en mi opinión debería ser una organización de resistencia, de huelgas [...]. Es solo en ésta donde se podrán agrupar las fuerzas obreras, la masa [...]. Por otro lado, los grupos secretos se encargarían de organizar la conspiración obrera» (Avilés, 2012): 244. 
abandonar un arma de propaganda tan expansiva y fácil de obtener como la dinamita? [...] natural es que escojamos un arma a la par potente y ruidosa y por ende capaz de hacerse oír de todos. [...] Nos repugna el empleo de la fuerza, sufrimos al tener que causar desolación y muerte, pues nuestra enseña es, como dijo Bakunin, "paz a los hombres y guerra a las instituciones», pero hallamos que, combatiendo a las instituciones y dejando en paz a los hombres, las primeras mantiénense incólumes y los segundos nos ofenden y escarnecen y de ahí que, contra nuestro gusto, tengamos que considerar a los hombres como parte integrante de las instituciones, como lo es el artillero del cañón en tiempo de guerra. Con todo, nos repugna tanto lastimar a los demás que, aun habiéndonos demostrado la práctica que una bomba colocada hace más propaganda que decenas de activos propagandistas, no se ha colocado una que no haya sido en respuesta a infamias cometidas contra nosotros [...]. Desengáñense los redactores de Las Dominicales ${ }^{73}$.

No parece casual que fuera Pedro Esteve el anarquista más influente de Paterson cuando el obrero italiano Gaetano Bresci salió de allí en 1900, atravesó el Atlántico y asesinó al rey Humberto de Italia, o que fuera el aglutinador del anarquismo ítalo-hispano-cubano en Tampa, Florida, cuando de allí salió el obrero aragonés Manuel Pardiñas y cruzó también el Atlántico, esta vez para asesinar en Madrid al presidente del Consejo, José Canalejas, en noviembre de 1912. Como señala el historiador Juan Avilés, «si bien la tendencia de los anarquistas era glorificar como héroes individuales a los que cometían atentados y eran condenados, es difícil creer que atentados complejos, en los que el autor del mismo llegaba a veces a otro país, fueran puramente individuales ${ }^{74}$.

En los dos casos citados, la conexión internacional para preparar atentados fue muy clara. En contra de lo que a veces se ha sostenido, el anarquismo no fue irracional y carente de organización, sino que hubo una planificación. Algunos de los atentados considerados actos puramente individuales, fueron en realidad fruto de decisiones tomadas por unas pocas personas. Influido por Kropotkin y sobre todo por Malatesta, Pedro Esteve asumió a la perfección la teoría de la doble estrategia, una abierta, que se desarrollaba a la luz del día, organizando a los obreros, agitándolos en las huelgas, etc., y otra secreta, en que solo unos pocos conocían la conspiración o el atentado que se estaba alentando o preparando. Esteve y su red de correligionarios publicaron periódicos que justificaban los actos de "propaganda por el hecho" y fueron, no solo

73 «Evolución del anarquismo», El Despertar, 20-6-1894, p. 1.

74 Avilés (2012): 245. 
plataforma de difusión de los atentados y de sus autores, sino de sus juicios, sus condenas, sus ejecuciones, las cartas escritas a sus familias, las últimas frases en el patíbulo..., todo ello con la idea de inspirar y promover otros atentados por el efecto contagio. De hecho, fue habitual que los autores de atentados individuales se inspirasen leyendo noticias sobre otros que les habían precedido y buscasen emularlos para pasar ellos también a la historia como mártires de la causa.

\section{CONCLUSIONES}

Por la propia naturaleza del movimiento anarquista, antiautoritario y antijerárquico, no hubo, al menos de forma explícita, una jefatura frente a una base, ni un centro frente a una periferia. Pero sí hubo una estrecha red de contactos y conexiones, tanto entre grupos como entre individuos concretos, que trascendieron el marco de la nación. Para entender el movimiento anarquista en toda su extensión es necesario estudiar quiénes fueron estas figuras y de qué forma tejieron intensos lazos a ambos lados del océano Atlántico. Gracias a la labor de enlace de una minoría cualificada de emigrados, hubo una gran fluidez en las relaciones entre grupos anarquistas de Europa y América, corrientes de solidaridad, debates ideológicos, etc. Atribuían a su función de propagandistas un papel esencial. Creían que esa era la forma de avanzar hacia la revolución. Escribieron mucho, sobre todo en los periódicos, que se intercambiaron en un prolífico canje transnacional.

En este artículo se ha analizado la función del periódico El Despertar dentro de la red transnacional de periódicos editados por Pedro Esteve, que hizo de enlace entre el anarquismo europeo y americano. En el primero que publicó, El Productor de Barcelona, se pudo apreciar el giro desde el anarcocolectivismo y las tácticas legalistas al anarcocomunismo y el discurso violento, partidario de la llamada "propaganda por el hecho", que fueron ya característicos de los que editó en Estados Unidos. De ideología anarcocomunista, próxima a las teorías de Kropotkin, y de tendencia organizadora, no por ello dejaron de estar a favor de la violencia revolucionaria, por entonces aceptada por casi todos los anarquistas por su importancia simbólica, como forma de llamar la atención sobre la injusticia e inspirar miedo a la burguesía. Creían que había que responder a la represión del Estado con la fuerza, defendían la violencia anarquista como respuesta a través del sabotaje, los atentados, el uso de la dinamita y el asesinato de gobernantes, descritos siempre como tiranos. Estos periódicos homenajearon año tras año al puñado de «valientes», con una gran empatía hacia el sufrimiento y la miseria de sus semejantes, que, 
con desprecio de su vida, se convertían en mártires de la causa. El culto a estos mártires se extendió, haciendo hincapié en la nobleza de su sacrificio y en su estoica actitud ante la muerte a la hora de su ejecución. En palabras de Esteve, «no en vano dieron gozosos sus vidas en holocausto a un ideal tan bello como el anarquista» ${ }^{75}$.

\section{Bibliografía}

Anderson, C. (2008). Bajo tres banderas. Anarquismo e imaginación anticolonial. Madrid: Akal. Avilés, J. (2006). Francisco Ferrer y Guardia: pedagogo, anarquista y mártir. Madrid: Marcial Pons.

- (2012). Terrorismo anarquista y terrorismo yihadí. Un análisis comparativo. Historia y Politica, 27, 227-249. Disponible en: https://bit.ly/35fgCL1.

Casanovas i Codina, J. (1992). Pere Esteve (1865-1925): un anarquista catalá a cavall de dos móns i de dues generacions. L'Avenç, Revista d'Història, 162, 18-22.

Díaz del Moral, J. (1967). Historia de las agitaciones campesinas andaluzas. Madrid: Alianza Editorial.

Esteve, P. (1900). A los anarquistas de España y Cuba. Memoria de la Conferencia Anarquista Internacional, celebrada en Chicago en septiembre de 1893. Paterson (Nueva Jersey): Imprenta El Despertar.

Fernández, F. (2000). Anarquismo en Cuba. Madrid: Fundación Anselmo Lorenzo.

Jensen, R. B. (2006). The United States, international policing and the war against Anarchist terrorism, 1900-1924. En D. C. Rapoport (ed.). Terrorism. Critical Concepts in Political Science (vol. 1). The First or Anarchist Wave (pp. 269-400). Londres; Nueva York: Routledge.

- (2014). The battle against anarchist terrorism: An international history, 1878-1934. Cambridge: Cambridge University Press. Disponible en: https://doi.org/10.1017/ CBO9781139524124.

Maitron, J. (1975). Le mouvement anarchiste en France (vol. 2). París: Maspéro.

Moya, J. C. (2010). El anarquismo argentino y el liderazgo español. En M. García Sebastiani (dir.). Patriotas entre naciones: elites emigrantes españolas en Argentina (1870-1940) (pp. 361-373). Madrid: Universidad Complutense.

Muñoz, V. (1974). Antología ácrata española. Barcelona: Grijalbo.

Sonn, R. D. (1989). Anarchism and Cultural Politics in Fin de Siècle France. Lincoln: University of Nebraska Press.

Sueiro Seoane, S. (2013). Un anarquista en penumbra. Pedro Esteve y la velada red del anarquismo transnacional. Alcores. Revista de Historia Contemporánea, 15, 43-66.

- (2014). Prensa y redes anarquistas transnacionales. El olvidado papel de J. C. Campos y sus crónicas sobre los mártires de Chicago en el anarquismo de lengua hispana.

75 Pedro Esteve (1900): 70-71. 
Cuadernos de Historia Contemporánea, 36, 259-295. Disponible en: https://doi. org/10.5209/rev_CHCO.2014.v36.46690.

- (2018). Anarquismo e independentismo cubano: las figuras olvidadas de Enrique Roig, Enrique Creci y Pedro Esteve. Espacio, Tiempo y Forma. Serie V, 30, 97-120. Disponible en: https://doi.org/10.5944/etfv.30.2018.21864.

Tinajero, A. (2007). El lector de tabaquería. Historia de una tradición cubana. Madrid: Verbum. Vega, B. (1984). Memorias. Contribución a la historia de la comunidad puertorriqueña en Nueva York. Puerto Rico: Ediciones El Huracán. 